\title{
Evaluation of Erectile Function in Patients Undergoing Hemodialysis
}

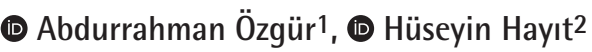 \\ ${ }^{1}$ Marmara University Pendik Training and Research Hospital, Clinic of Urology, İstanbul, Turkiye \\ 2University of Health Sciences Turkiye, Sultan 2. Abdülhamid Han Training and Research Hospital, Clinic of Urology, Istanbul, Turkiye
}

\section{What's known on the subject? and What does the study add?}

Many clinical problems related to CKD disappear with dialysis treatment, ED complaints continue during the treatment period. ED in patients with CKD is reported at a rate of $50-80 \%$ and the etiology of ED in this group is multifactorial. Concomitant systemic diseases are important. One of the possible causes of ED in CKD patients is disorders in hypothalamic-pituitary-gonadal ax. As a result, abnormalities in many hormonal values can be seen. With this study we show that elevated prolactin alone was not detected as the cause of erectile dysfunction in dialysis patients.

\begin{abstract}
Objective: This study aimed to evaluate the erectile function in patients undergoing dialysis due to chronic renal failure and ascertain the causes of erectile dysfunction (ED).

Materials and Methods: Patients undergoing hemodialysis admitted to our outpatient clinic with an erectile function evaluation between February and August 2019 were retrospectively investigated. The International Index of Erectile Function form erection scores, hormone levels, total dialysis durations, libido, nocturnal erection, and other additional diseases were recorded.

Results: A total of 28 patients had all mentioned values. The mean age of patients was 58.6 (35-75) years. In the study group, only two of all patients (7.14\%) had no erection complaints and both of them were under 40 years old. Approximately 93\% of patients had ED and $79 \%$ of this patient group was over 50 years old. The dialysis duration of patients ranged between 8-180 months. Patients' serum prolactin, glucose, testosterone, luteinizing hormone values, and erection scores were analyzed with Paired-Samples test. Glucose levels were found to be significant.

Conclusion: The ED percentage is high, especially in patients over 50 years old with hemodialysis. The presence of diabetes in this patient group increased the erectile problems. Elevated prolactin alone was not detected as the cause of ED in patients undergoing dialysis. Further studies with larger series are necessary due to the limited number of patients in the study group; however, the current study suggested an investigation for ED in patients undergoing hemodialysis.
\end{abstract}

Keywords: Erectile dysfunction, hemodialysis, prolactin

\section{Introduction}

Chronic kidney failure (CKD) is a life-threatening with a poor prognostic disease. CKD is seen in all age groups; however, it often occurs in the elderly. In a study, 2126 men were evaluated, and erectile dysfunction (ED) rates were $\sim 35 \%$ in the $40-60$ years age group and $\sim 70 \%$ in the $60-70$ years age group (1). The adult patient group with CKD corresponds to $>10 \%$ of the total world population and its rate is increasing daily (2).

Dialysis treatment (peritoneal or hemodialysis does not make a difference) has a significant impact on the patient's physical and psychosocial aspects. Stressful conditions, such as exhausting dialysis programs, associated medical treatments, fluid and dietary restrictions, frequent recurrent infections, ED, and possible job loss are serious problems that patients face in their future life (2).

Sexual activity has an important place in the lives of patients with CKD; however, these patients rarely express ED. Despite the presence of $E D$, few patients report this problem to their doctor. Many clinical problems related to CKD disappear with dialysis treatment; however, ED complaints continue until the treatment period. ED in patients with CKD is reported at a rate

Correspondence: Abdurrahman Özgür MD, Marmara University Pendik Training and Research Hospital, Clinic of Urology, İstanbul, Turkiye Phone: +90 5053946193 E-mail: aozgur2000@yahoo.com ORCID-ID: orcid.org/0000-0001-9123-9161

Received: 30.12 .2021 Accepted: 15.01.2021

Cite this article as: Özgür A, Hayıt H. Evaluation of Erectile Function in Patients Undergoing Hemodialysis. J Urol Surg 2021;8(3):198-201.

๑Copyright 2021 by the Association of Urological Surgery / Journal of Urological Surgery published by Galenos Publishing House. 
of 50\%-80\% (3), and low-dose tadalafil therapy was reported as an effective option (4). The ED etiology in this group is multifactorial. Concomitant systemic diseases are important. One of the possible causes of ED in patients with CKD is hypothalamic-pituitary-gonadal axis disorders; therefore, many hormonal value abnormalities were seen (5).

This study aimed to evaluate the erectile function of patients undergoing chronic renal failure (CRF)-induced hemodialysis treatment, determine the current ED rate, and reveal the possible causes of ED.

\section{Materials and Methods}

This study was approved by the Ethics Committee of the University of Health Sciences Turkiye to which our hospital is affiliated (approval number: 20/121, date: 24.04.2020), and patients undergoing hemodialysis admitted to our outpatient clinic and treated for erectile function problems between February-August 2019 were retrospectively evaluated.

Recorded in the study are the following: age of patients; International Erectile Function Form erection scores (Table 1) for ED evaluation; hormone values [luteinizing hormone (LH), prolactin, and testosterone] and serum glucose levels (Table 2), which were examined in the morning; total dialysis times; presence of libido and night erections; and other existing systemic diseases, such as diabetes and hypertension.

\section{Statistical Analysis}

The Statistical Package for the Social Sciences 16.0 for Windows

Table 1. Classification according to International Erectile Function Form (IIEF) erection evaluation score

\begin{tabular}{|l|l|l|}
\hline Topic & IIEF questions & Total score 1-30 \\
\hline \multirow{4}{*}{ Erectile function } & \multirow{3}{*}{$1,2,3,4,5,15$} & 0 -10: Serious \\
\cline { 3 - 3 } & & 11-16: Medium \\
& & 17-21: Light-medium \\
\cline { 3 - 3 } & & $22-25:$ Light \\
\cline { 3 - 3 } & & $26-30:$ None \\
\hline
\end{tabular}

Table 2. Patients glucose vs hormone levels

\begin{tabular}{|l|l|l|l|l|l|}
\hline & $\mathbf{n}$ & Minimum & Maximum & Mean & $\begin{array}{l}\text { Standard } \\
\text { deviation }\end{array}$ \\
\hline $\begin{array}{l}\text { Prolactin (ng/ } \\
\mathrm{mL})\end{array}$ & 28 & 6.0 & 79.0 & 23,427 & 17,4275 \\
\hline $\begin{array}{l}\text { Testosterone } \\
\text { (nmol/L) }\end{array}$ & 28 & 1.0 & 9.0 & 4,104 & 1,8863 \\
\hline $\mathrm{LH}(\mathrm{IU} / \mathrm{L})$ & 28 & 4 & 13 & 8.78 & 2,644 \\
\hline $\begin{array}{l}\text { Glucose (mg/ } \\
\mathrm{dL})\end{array}$ & 28 & 75 & 287 & 132.57 & 56,004 \\
\hline LH: Luteinizing hormone & \multicolumn{5}{|l}{} \\
\hline
\end{tabular}

program and Paired-Samples test were used for the statistical evaluation of results.

\section{Results}

On the specified dates, 70 patients undergoing hemodialysis were examined in the outpatient clinic. A total of 28 patients, with all available data as mentioned above constituted our group.

The mean age of the patients was 58.6 (35-75) years, wherein $21.43 \%$ were under 50 years old and 50\% were between 60 and 75 years old. In the study group, only two (7.14\%) patients under the age of 40 were observed to have no erection problems, whereas 93\% of the total patients had erection complaints. Of this patient group, 78.6\% are over 50 years old. Severe to moderate ED was observed in this group. This study revealed a statistically significant relationship between patients' age and ED scores $(p=0.019)$.

The duration of dialysis was 56.7 (8-180) months on average. No statistically significant relationship was found between the total dialysis time and ED scores.

Regardless of dialysis duration, in parallel with increased age, increased ED complaints of patients were observed.

The dependent sample analysis between serum prolactin, glucose, testosterone, LH values, and erection evaluation scores to determine the causes of ED complaints of patients revealed a significant relationship only with the glucose level $(p=0.004)$. No significant relationship was found between other hormone levels and ED.

Severe ED was observed in 16 patients accompanied by diabetes in the total group.

Eight patients had elevated serum prolactin levels (prolactin> $=20 \mathrm{ng} / \mathrm{mL}$ ), whereas in 75\% had normal libido. In the group with normal prolactin levels, only $70 \%$ of the patients' libido was considered normal.

In the study group, with a cut-off value of $2 \mathrm{nmol} / \mathrm{L}$, only two of the patients had low testosterone levels (7.14\%).

LH levels were normal in all patients.

\section{Discussion}

CKD is a common, life-threatening disease with increasing frequency recently and has poor prognostic characteristics. CKD is seen in all age groups; however, it often occurs among adults. The adult patient group accounts for $>10 \%$ of the total world population (2). 
In the analysis of the Massachusetts Male Aging Study data, an exponentially increasing ED over the years was emphasized. In the study, 1290 men between the ages of 40-70 years were evaluated and revealed an increased complete ED rate from 5.1\% to 15\% and an increased average ED rate from 17\% to 34\% from the age of 40 to 70 years (6). In the 40-49 years age group, an increase of $12.4 / 1000$ new cases per year were reported, 29.8/1000 in the 5060 years age group, and $46.4 / 1000$ in the $60-70$ years age group (7). In patients undergoing dialysis, ED rates are stated in $65 \%$ of patients with peritoneal dialysis and 75\% with hemodialysis (1). In our study group, only two (7.14\%) patients did not have an erection complaint, who were under 40 years of age; however, the total ED rate was quite high which draws attention. In total, $93 \%$ of patients had complaints of erection.

In a study by YıImaz and Özaltın (8), no significant correlation was observed between the age and ED in patients undergoing peritoneal dialysis. However, in our study, $78.6 \%$ of patients with ED complaints were over 50 years of age who had moderateserious ED. In the study, a statistically significant relationship was found between patients' age and ED scores ( $p=0.019)$.

Changes in hormone levels are expected in patients with CRF. Decreased testosterone levels and elevated $\mathrm{LH}$ and prolactin levels are observed (9). Low testosterone and high prolactin levels lead to loss of libido (3). Prolactin interacted with opioid and serotoninergic systems that contribute to sexual behavior regulation. An excessively high level of prolactin destroys dopamine receptors and thus, sexual function loss occurs. In men, it causes complaints, such as ED, infertility, and gynecomastia (10). The most common male sexual dysfunction due to hyperprolactinemia is ED with low libido (11). In our study group, eight patients had elevated serum prolactin levels (prolactin $>=20 \mathrm{ng} / \mathrm{mL}$ ), whereas $75 \%$ has normal libido. In the group with normal prolactin levels, only $70 \%$ of the patients' libido was considered normal; therefore, no statistically significant correlation was found between prolactin level and ED and libido. Additionally, only two of our patients had low testosterone levels (7.14\%). LH levels were normal in all patients.

Diseases, such as diabetes and hypertension, which are frequently accompanied by CKD, also increase the risk of ED. Especially, the presence of diabetes and CKD duration is seen as an important predisposing factor for ED (12). In our study group, all 16 patients with diabetes had severe ED, which compliments the literature; however, no significant relationship was found between the dialysis duration and ED score in our study.

\section{Study Limitations}

However, the main limitation of our study was the limited number of patients. Further studies with larger series are needed due to the very limited number of studies. However, data from this study provide a basis for routine questioning of the presence of $E D$ in patients undergoing dialysis.

\section{Conclusion}

The percentage of ED is high, especially in the group of patients over 50 years of age that is undergoing dialysis treatment with diabetes. According to our study, prolactin level and dialysis times cannot be evaluated as the cause of erection problems in patients undergoing dialysis.

\section{Ethics}

Ethics Committee Approval: This study was approved by the Ethics Committee of the University of Health Sciences Turkiye to which our hospital is affiliated (approval number: 20/121, date: 24.04.2020).

Informed Consent: Retrospective study.

Peer-review: Externally peer-reviewed.

\section{Authorship Contributions}

Concept: A.Ö., H.H., Design: A.Ö., Data Collection or Processing: A.Ö., H.H., Analysis or Interpretation: A.Ö., Literature Search: A.Ö., Writing: A.Ö., H.H.

Conflict of Interest: No conflict of interest was declared by the authors.

Financial Disclosure: The authors declare that they have no relevant financial.

\section{References}

1. Selvin $E$, Burnett $A L$, Platz EA. Prevalence and risk factors for erectile dysfunction in the US. Am J Med 2007;120:151-157.

2. Keskin G, Babacan Gümüş $A$, Taşdemir Yiğitoğlu G. Sexual dysfunctions and related variables with sexual function in patients who undergo dialysis for chronic renal failure. J Clin Nurs 2019;28:257-269.

3. Levy NB. Sexual adjustment to maintenance hemodialysis and renal transplantation: national survey by questionnaire: preliminary report. Trans Am Soc Artif Intern Organs 1973;19:138-143.

4. Bolat MS, Özer I, Cinar 0 , Akdeniz E, Aşcı R. The efficacy of low-dose tadalafil in patients undergoing hemodialysis with end-stage renal disease. Ren Fail 2017:39:582-587.

5. Fiuk JV, Tadros NN. Erectile dysfunction in renal failure and transplant patients. Transl Androl Urol 2019;8:155-163.

6. Feldman $H A$, Longcope $C$, Derby $C A$, Johannes $C B$, Araujo $A B$, Coviello $A D$, Bremner WJ, McKinlay JB. Age trends in the level of serum testosterone and other hormones in middle-aged men: longitudinal results from the Massachusetts male aging study. J Clin Endocrinol Metab 2002;87:589-598.

7. Johannes CB, Araujo AB, Feldman HA, Derby CA, Kleinman KP, McKinlay JB. Incidence of erectile dysfunction in men 40 to 69 years old: longitudinal results from the Massachusetts male aging study. J Urol 2000;163:460-463. 
8. Yılmaz M, Özaltın G. Sexual problems of individuals with peritoneal dialysis therapy. Firat Health Services Journal 2010;5:97-112.

9. Chryssicopoulos A, Koutsikos D, Kapetanaki A, Agroyannis B, Tzanatos H, Rammos G, Fourtounas C, Kopelias I, Bossiolis B, Darema M, Zourlas PA. Evaluation of the hypothalamic-pituitary axis in uremic males using dynamic tests. The possible role of testicular inhibin: a preliminary report. Ren Fail 1996;18:911-921.

10. Güzel Ö, Atan A, Aslan Y. Hiperprolaktinemi ve erektil disfonksiyon. Androloji Bülteni 2018;20:90-94.
11. Majidi Zolbanin N, Zolali E, Mohajjel Nayebi A. Testosterone replacement attenuates haloperidol-induced catalepsy in male rats. Adv Pharm Bull 2014;4:237-241.

12. Mesquita JF, Ramos TF, Mesquita FP, Bastos Netto JM, Bastos MG, Figueiredo AA. Prevalence of erectile dysfunction in chronic renal disease patients on conservative treatment. Clinics (Sao Paulo) 2012;67:181-183. 